\title{
Yüksek Katlı Yapının Sarsma Tablası Üzerinde Deprem Performansının İncelenmesi
}

\author{
Elif AĞCAKOCA ${ }^{1 *}$ \\ Sakarya Üniversitesi, Mühendislik Fakültesi, Inşaat Mühendisliği Bölümü, Sakarya, Türkiye. \\ elifd@sakarya.edu.tr
}

\section{Özet}

Yerkabuğu içinde oluşan kırılmadan dolayı ortaya çıkan deprem titreşimleri, dalgalar halinde yayılarak yapıları etkilemektedir. Yapılar tasarım aşamasında, etkileneceği deprem titreşimlerini karşılayacak performansa sahip olacak şekilde tasarlanmalıdır. Teknolojideki ilerlemeler sayesinde, mevcut ya da üretilmiş kayıtlı ivme değeri kullanılarak, yapıların kayıtlı ivme değerlerinin uygulanması sırasında göstereceği performans gözlemlenebilmektedir. Çalışmamızda sarsma tablasına balsa ağacından yapılan 30 katlı bina yerleştirilerek, mevcut kayıtlı ivme değerlerinin uygulanması yardımıyla, yapının dinamik karakteristikleri belirlenmeye çalışılmıştır. Yapının en üst katına yerleştirilen ivme ölçerden elde edilen değerler sayesinde çatı ivme ve deplasman değerlerinin hesaplanması sağlamıştır. Ayrıca yapılan bu deneysel çalışma, Sap2000 programında bulunan Zaman Tanım Alanında Hesap Yöntemi yardımıyla, nümerik analizi yapılmıştır. Nümerik analiz ve deneysel çalışma sonuçlarından elde edilen ivme, hız ve yer değiştirme değerleri birbiri ile kıyaslanmıştır. Yapılan kıyaslama sonucunda, oluşturulan sonlu eleman modelinin deneysel model davranışını yaklaşık olarak doğru tespit edildiği görülmüştür.

Anahtar Kelimeler: Yüksek katlı yapılar, sarsma tablası, dinamik analiz, performans

\section{Investigation of High-Rise Structure with Shaking Table}

\begin{abstract}
Earthquake vibrations caused by fractures in the Earth's crust spread in waves and cause buildings to be affected. During the design phase, the buildings should be designed according to the performance to meet the earthquake vibrations. Today, thanks to the advances in technology, the performance of the structures under the existing or produced earthquake records can be observed. This study, a 30-storey building made of Balsa wood was placed on the shaking table, then vibration was given to the building using the existing earthquake records so that the dynamic characteristics of the building were determined. Roof acceleration and displacement values were calculated with the help of accelerometers placed on the top floor of the building. In addition to this experimental study, numerical analysis was performed by using the calculation Time-History in the Sap2000 program. Acceleration-velocity-displacement values obtained from experimental and finite element solutions were compared. As a result of the comparison, the dynamic characteristics of the structure was found that the finite element model was determined to be approximately correct for the experimental model behavior.
\end{abstract}




\section{GIRIŞ}

İnsanoğlu, çevrenin yarattığı olumsuz etkilere karşı hayatını devam ettirebilmesi için yapılara ihtiyaç duymaktadır. Yapıların hem çevresel etkilere, hem de insanoğlunun artan ihtiyaçlarına cevap verebilecek nitelikte olması gerekmektedir. İhtiyaçların çeşitlenmesi ve nüfusun belirli yerlerde yoğunlaşması, yapıların niteliklerini ve sahip olduğu kat adetlerini arttırmaktadır. Günümüzde yüksek katlı yapılar özellikle nüfus yoğunluğunun fazla olduğu bölgelerde, alışveriş merkezi yada sağlık kurumlarında tercih edilmektedir. Ayrıca arsa maliyeti yüksek olan yerleşim yerlerinde, yüksek katlı yapılan yapılarda, kat adedinin artması arsa maliyetini azalttığı için tercih edilmektedir. Yapının kat adedinin artması, taşıyıcı sistemde oluşan iç kuvvetlerin ve boyutlarının artmasına dolayısı ile yapı maliyetinin yükselmesine sebep olmaktadır.

Ülkemizde ve dünyada bulunan yapılar çok çeşitli dinamik yükleme durumu ile karşılaşabilmektedir. Bilinen ve en sık maruz kalınan dinamik yük deprem yükü olmaktadır. Yapılar yıllar içinde deprem gibi dinamik etkilere maruz kaldığında ağırlıkları ile orantılı olarak bu yüklerden etkilenmekte ve hasar görebilmektedir. Deprem sonrası hasar gören yapılar incelendiğinde, en büyük sorunun yapının kat ağırlığı yada adedinden değil, tasarım aşamasında dikkate alınmayan yada yanlış alınan yüklerden olduğu anlaşılmaktadır. Türkiye Bina Deprem Yönetmeliği 2018 (TBDY2018)'de belirtildiği gibi burulma düzensizliği (A1), döşeme süreksizliği (A2), planda çıkıntıların olması (A3), komşu katlar arası dayanım düzensizliği (B1), komşu katlar arası rijitliktlik düzensizliği (B2), taşıyıcı sistemin düşey elemanlarının süreksizliği (B3) binalarda hasar oluşmasına sebep olan en büyük etken olmaktadır. Literatürde deprem yüküne maruz kalan yapılarda, rijitlik etkisi incelenmiştir [1]. Bunun yanı sıra simetrik bir yapının büyük konsollara sahip olması durumunda [2] yada taşıyıcı sistemi perde ve çerçeveden oluşan [3], yadakatlar arası farklı rijitliğe sahip yapının analizi incelenmiş, bu parametrelerin yapıda oluşturduğu değişimler değerlendirilmiştir [4]. Ayrıca, kesme kuvveti etkisine maruz yapılarda, perde geometrisinin, perde doğrultusunun, yapının sünekliği ve rijitliğinin, farklı zemin durumlarının yapıda oluşturduğu etki incelenmiştir $[5,6,7,8]$. Sarsma tablasında merkezi çelik çapraza sahip yapının deprem yükü etkisi altındaki davranışı incelenmiştir $[9,10]$. Ayrıca literatürde sarsma tablasında soğukta şekil verilmiş çelikten üretilmiş 1/1 boyutlu [11] yada daha küçük boyutlu yapının deprem yükü altındaki davranışı incelenmiştir [12]. Ülkemizde laboratuvar ortamında $1 / 1$ ölçekli gerçek boyutlu olarak oluşturulan yapının sarsma tablası yardımıyla kayıtlı ivme değerleri altında dinamik davranışının incelenmesi henüz gerçekleştirilememektedir. Ancak, belirli bir ölçekte küçültülerek inşa edilen maket yapıların sarma tablası yardımıyla incelenmesi ve değerlendirilmesi yapının deprem etkisi altındaki davranışına ışık tutabilmektedir. Bu noktadan hareketle; çalışmada her iki asal eksen doğrultusunda simetrik olan, 30 katlı perdeli bir yapının, mevcut deprem kayıtları ile zorlanarak, deprem kuvvetini yapı davranışı üzerine etkisi araştırılmıştır. Ayrıca yapı elemanlarına yapılan güçlendirmeler sonucunda yapının dinamik karakteristiklerinde olan doğal frekans değerinde artış olabilmektedir [13].

Çalışmada yapının sonlu eleman yöntemi yardımıyla bilgisayar ortamında gerçekleştirilen analiz sonuçları, sarsma tablasından elde edilen deney sonuçları ile karşılaştırılmıştır. İncelenen yapıda, üzerindeki yükleme durumu altında sonlu eleman yöntemi yeterli yaklaşımı sağlamıştır. Bu yaklaşım ispat edildikten sonra, farklı yükleme yada farklı geometrik özelliğe sahip yapının farklı yükleme durumları altında göstereceği performans yap1 inşaa edilmeden tahmin edilebilecektir. Böylece yap1 tasarım aşamasında iken karşılaşabileceği yükleme riskleri değerlendirilip, yapıda oluşacak hasar durumu TBDY2018 göre sınıflandırılabilecektir. Ayrıca bu çalışmadan sonra, yapı hangi malzemeden üretilirse üretilsin, sonlu eleman yönteminde malzeme ve eleman davranışı doğru yaklaşım ile tanımlanırsa, yapının farklı yükleme altındaki davranışının tahmin edileceği, yapılan çalışma ile gösterilmiştir.

\section{MALZEME ÖZELLİKLERI VE YAPI MODELİ}

\subsection{Malzeme Özelliği}

Model yapıyı oluşturan elemanlar balsa ağacından üretilmiş çıtalar ve levhalar kullanılarak inşa edilmiştir. Model yapıda balsa levha ve çıtalarının kullanılmasının ana nedeniyle malzemenin hafif olmasıdır. Böylece 
inşaa edilen yapının sarsma tablası üzerine yerleştirilmesi ve kaldırılmasının kolay olacaktır. Ayrıca literatürde benzer yapı malzemesi ile oluşturulmuş ve incelenmiş yapı modellerinin var olması, çalışmada modellenen binada balsa çıta ve levhalarının kullanılmasının yolunu açmıştır.

Balsa ağacı, Meksika ve Brezilyada yetişen 30 m yüksekliğine ulaşan bir ağaç türüdür. Özellikle model bina ve uçak maketi yapımında kullanılmaktadır. İşlenme durumuna göre balsa kerestesi 3 farklı yoğunlukta elde edilmektedir [14].

Model yapının inşasında kullanılan balsa çıta ve levhaları eksenel çekme deneyine tabi tutularak balsa malzemenin mekanik özellikleri Tablo 1'degösterildiği gibi tesbit edilmiştir.

Tablo 1. Balsanın mekanik özellikleri

\begin{tabular}{ll}
\hline Elastisite modülü $(\mathrm{N} / \mathrm{mm} 2)$ & 2100 \\
Birim hacim ağırlığ $1(\mathrm{~kg} / \mathrm{m} 3)$ & 190 \\
Poison oranı & 0.2 \\
\hline
\end{tabular}

Yapı oluşturan kolon ve kiriş elemanlarının birbirine rijit olarak bağlanmasını sağlamak için Pattex marka, 2k Profesyonel Hızlı Yapıştırıcı ve Aktivatör kullanılmıştır. Yapıştırıcı uygulanırken, yüzeyin temiz, yağdan ve tozdan arındırılmış olmasına dikkat edilmiştir. Uygun şartlar sağlandıktan sonra yapıştırıcı birleştiği yüzeyler arasında tam penetrasyonu sağlamıştır. Yapılan deneysel çalışmada yapıştırıcının birleştirdiği bağlantı noktasında hasar oluşmuş ancak kopmamıştır. Bu durum yapıştırıcının kendinden beklenen performansı sağladığını göstermiştir.

\subsection{Yapı Modeli}

Deprem gibi dinamik yük etkisi altında bulunan betonarme veya çelik malzemesinden birebir boyutlu üretilmiş yapı davranışının, deneysel olarak belirlemesi ülkemiz şartlarında mümkün değildir. Bu yüzden küçük ölçekli ve kolay işlenebilecek malzemelerden üretilen yapılardan faydalanılarak, deneysel olarak yapının dinamik davranışı belirlenebilmektedir. Bir yapı modellerken dikkat edilen yönetmelik ve standart kuralları, model yapı yaparken de geçerli olmaktadır. Yönetmelik dahilinde bir yapıyı modellerken, yapıyı etkiyen deprem kuvvetini azaltmak için, yönetmelik dahlinde, yapı elemanlarını mümkün olduğunda küçük boyutta seçilmesi maruz kalacağı deprem kuvvetini düşürecektir. Yapıdaki bu durumu model bina için simule edilirken, yapının üst katlarındaki kolon ve kirişlerinin yerleştirilmesinde, daha hafif olan düşük yoğunluktaki balsa çıta ve levhalarının kullanılması tercih edilmiştir. Buna paralel olarak alt kat kolon ve kiriş elemanları oluşturulurken yoğunluğu yüksek ve daha rijit olan balsa çıta ve levhaların kullanılması tercih edilmiştir. Ayrıca çalışmada kullanılan model yapıda kat döşemeleri 4 farklı geometriye sahip olacak şekilde oluşturulmuştur. Oluşturulan geometriler Şekil 1a,b,c,d'de gösterilmiştir. Bunların yanı sıra, model binada sabit ve hareketli yükü temsil etmesi için, 3 katta bir yapıya 1.5 kg'lık ağırlıklar eklenerek toplu kütleli sistem davranışı elde edilmeye çalışılmıştır. 1.5 kg'lık ağırlık belirlenirken, yapının kullanım amacı ve geometrisi dikkate alınmıştır. Ayrıca çalışmada kat ağırlıklarının sonuca etkisini en aza indirmek için farklı deprem yüklerinin uygulandığı üç farklı deneysel çalışmada 1.5 kg'lık ağırlık, yapıda aynı kata ve aynı noktaya uygulanmıştır.

Model yap1, 40x40 cm taban alanına sahip olup, $155 \mathrm{~cm}$ yüksekliğinde ve 30 katlı bir konut olarak tasarlanmıştır. Simetrik olarak modellenen bina, mimari olarak 30 kat boyunca değişim gösteren 4 farklı kat planına sahip olacak şekilde oluşturulmuştur. Yapının 1. kat planında yer alan en diş akstaki kolonlar üst katlarda devam etmemektedir. Ayrıca yapının 2. kat köşe kolonlarının yerine konsollar yapılarak, zemin katın sahip olduğu kat alanı 2. katta da korunmaktadır. Konsollar $60 \mathrm{~mm}$ lik en kesit boyutunda ve $4 \mathrm{~cm}$ uzunluğunda olup, model binanın kat çevresinin tamamında bulunmaktadır. Model binanın ilk 9 katının her biri $1600 \mathrm{~cm}^{2}$ kat alanına sahiptir. Yapının 9-18 katlar arasında, istenilen mimarinin verilebilmesi için 
konsollar yapılmamış ancak 19. kattan sonra tekrar yapıya konsollar yapılarak, mimariye uygun hale getirilmiştir. Bina toplam $41.700 \mathrm{~cm}^{2}$ kat alanına sahiptir. Model yapıya ait kolonlar, kirişler ve çapraz elemanlar $60 \times 60 \mathrm{~mm}$ ebadında balsa çubuklardan, perdeler ise $40 \times 3 \mathrm{~mm}$ boyutunda balsa plağından yapılmıştır. Zemin kat yüksekliği $10 \mathrm{~cm}$, normal kat yükseklikleri ise 5 'er $\mathrm{cm}$ olacak şekilde belirlenmiştir. Toplam model yapı ağırlığı 4,5 kg olarak ölçülmüştür. Yukarıda anlatılan özelliklere sahip olan model yapının tepe noktasına ivmeölçer sabit bir şekilde yerleştirilmiştir. Sarsma tablası üzerine yerleştirilen model binaya, ivme-zaman kayıtları olan deprem yükü uygulanmıştır. Yapının tepe noktası ve taban bölgesine yerleştirilen ivmeölçerler sayesinde yapının gerçek zamanlı deprem hareketi etkisi altındaki dinamik davranışı incelenmiştir.

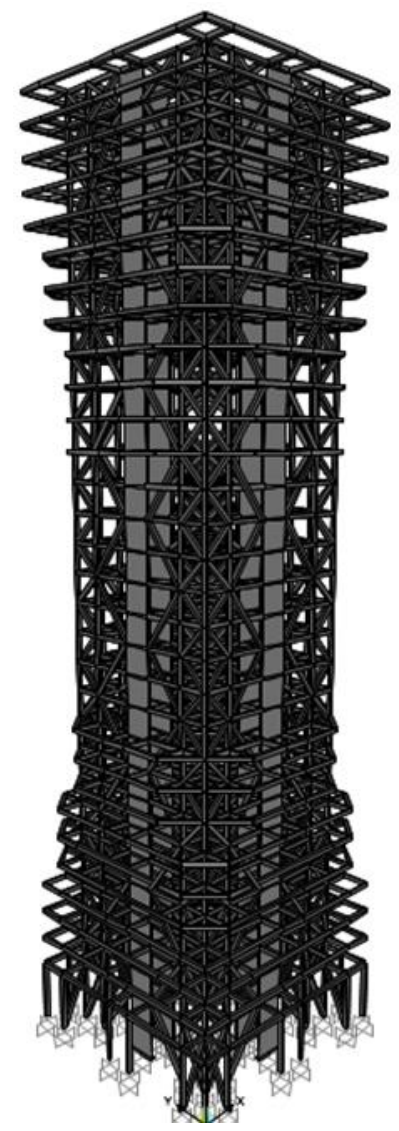

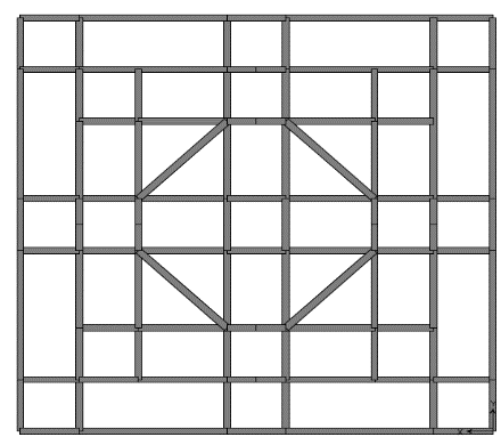

(a) 1-4 katlar ve 26-30 kat aras

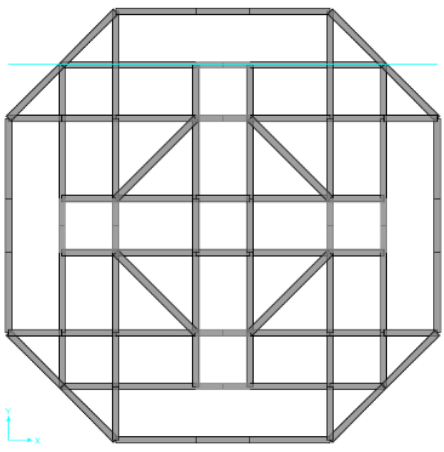

(c) 8-10 katlar ve 20-22 katlar

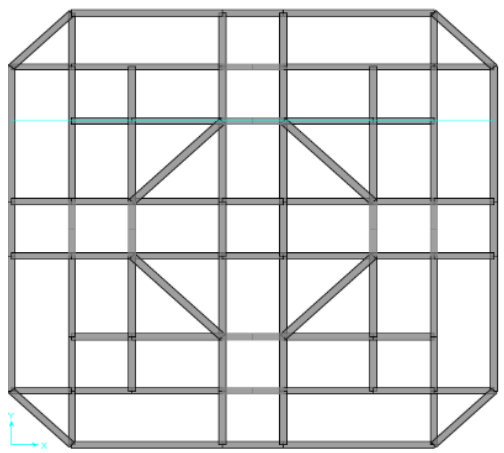

(b) 5-7 katlar ve 23-25 kat aras1

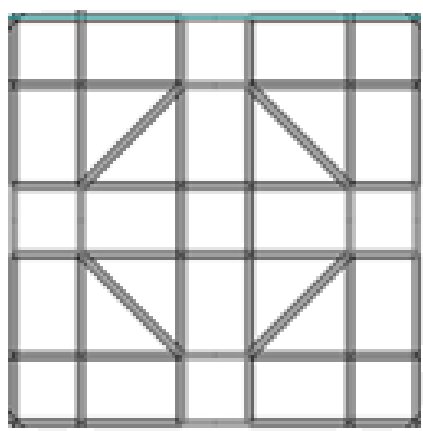

(d) 11-19 kat aras1

Şekil 1. Model yapı üç boyutlu görünüşü ve kat planları

\section{ANALIZ}

\subsection{Filitreleme}

Sarsma tablasına bağlı bulunan veri toplama sisteminde veri filtreleme algoritması bulunmaktadır. Filitreleme algoritması deney esnasında ortamda bulunan gürültünün filtrelenmesi için kullanılmaktadır. Çalışmada kullanılan veri toplama sisteminde Butterwort filtreleme işlemi 1,5-15 Hz arasındaki verileri filtrelemek için kullanılmıştır. Ayrıca deney sonrası elde edilen ivme kayıtları Siesmo Signal programı kullanılarak filtre edilmiştir. 


\subsection{Doğal Titreşim Frekansının Belirlenmesi}

Model bina deney düzeneğine yerleştirildikten sonra deprem kuvveti vermeden ivme ölçerlerden veriler alınarak model yapıya ait doğal titreşim frekansları bulunmaktadır. Doğal titreşim frekansının bulunurken yapı belli bir oranda itilir ve yapının serbest titreşim yapması sağlanır. İvme ölçerlerden alınan ivme-zaman değerleri Fourier dönüşümü ile frekansa bağlı fonksiyona dönüştürülmektedir. Çizilen grafikteki maksimum değer doğal titreşim frekansını vermektedir. Yapının doğal titreşim frekansının elde edilmesinde Siesmo Signal programında bulunan Fourier dönüşümünden yararlanılmaktadır. Model yapının doğal frekansını elde etmek için serbest titreşim uygulanmış ve elde edilen ivme zaman kayıtları Siesmo Signal programı yardımı ile Şekil 2'de gösterildiği gibi filtre edilmiştir.

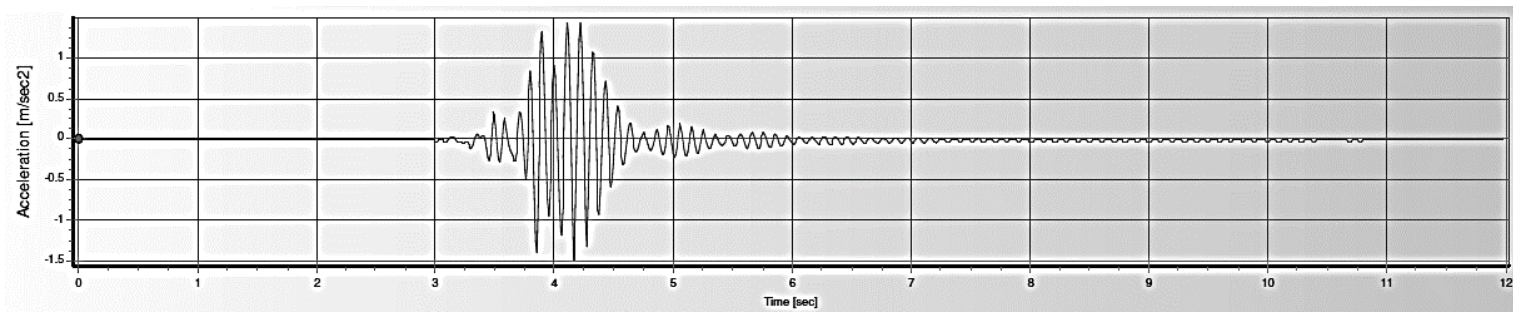

(a)

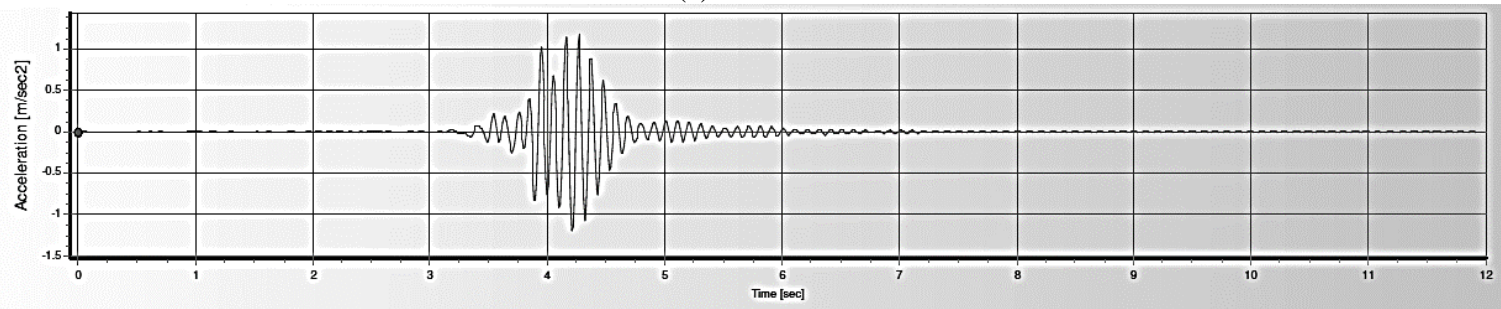

(b)

Şekil 2. Model yapının serbest titreşimin ivme ivme-zaman grafiği, a)Filitre edilmemiş, b) Filitre edilmiş

\subsection{Sönüm Oranı}

Yapının sönüm oranını belirlerken 3 farklı yöntem kullanılmaktadır. Serbest titreşim denklemi yardımıyla, logaritmik azalım yardımıyla, yarım güç bant kalınlığı yöntemi ile sönümün belirlenmektedir [15].

\section{Serbest Titreşim Denklemi Kullanılarak Sönüm Oranının Belirlenmesi}

$$
\mathrm{u}(\mathrm{t})=\sum \emptyset_{n}\left[e^{-\zeta_{n}} n^{w} n^{t}\left[u_{n}(0) \cos _{D^{t}}+\frac{u^{n}(0)+\zeta_{n} w_{n} u_{n}(0)}{w_{D}} \sin w_{D}^{t}\right]\right]
$$

$u_{n}(t)$ zamana bağlı yer değişimini $\emptyset_{n}, \zeta n$ ve $w_{n}$ sırası ile $\mathrm{n}$. mod şekil vektörünü, sönüm oranını ve doğal frekansı, t zamanı, $u_{n}(0)$ başlangıçtaki yer değişimini $w_{D}$ sönümlü doğal frekansı, $u^{n}(0)$ hızı göstermektedir. $\mathrm{Bu}$ denklemde bulunan tüm parametreler deney sirasinda deney numunesinin sadece tek modda hareket etmesi sağlanarak, ivme ölçerlerden alınan verilerden elde edilmektedir [15].

Logaritmik Azalım İle Sönüm Oranının Belirlenmesi

Deneyde kullanılan yapıya ait serbest titreşim kayıtları kullanılarak logaritmik azalım yöntemi ile yapının sönümü hesaplanabilir.

$$
\zeta=\frac{1}{2 \pi j} \ln \frac{u_{i}}{u_{i+j}}
$$

$\zeta$ ifadesi sönümü $u_{i}$ ve $u_{i+j}$ genlik değerini, $\mathrm{i}$ ve $\mathrm{j}$ ise devir sayısını göstermektedir. 


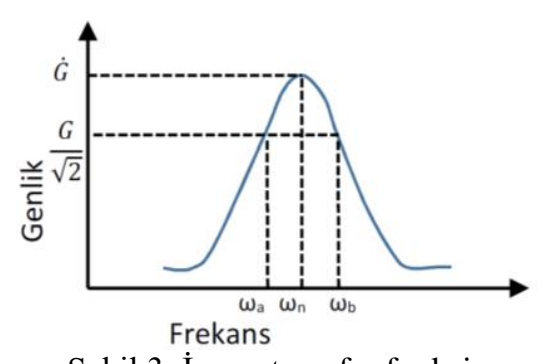

Şekil 3. İvme-transfer fonksiyonu

Yarım güç bant kalınlı̆̆ı yöntemi ile sönüm hesaplanması

$$
2 \zeta=\frac{w_{\mathrm{b}}-w_{\mathrm{a}}}{\mathrm{w}_{\mathrm{n}}}
$$

Formülde bulunan $\mathrm{w}_{\mathrm{b}}$ doğal titreşim frekansını, $\mathrm{w}_{\mathrm{a}}, \mathrm{w}_{\mathrm{b}}$ Şekil 3'de bulunan $G / \sqrt{2}$ noktasından çizilen çizginin eğriyi kestiği noktadaki ferens değerini ifade etmektedir. $\zeta$ ise sönüm oranını ifade etmektedir [16]. Yapının serbest titreşim metodu kullanılarak sönümü \%1.3 olarak bulunmuştur.

\section{DENEY DÜZENEĞi}

Sarsma tablasını kullanarak yada farklı deneysel çalışmalar sayesinde betonarme çelik yada kompozit yapıların[17] dinamik davranışları belirlenebilmektedir [18]. Deneyler Sakarya Üniversitesi İnşaat Mühendisliği laboratuvarında bulunan $1 \times 1 \mathrm{~m}$ boyutundaki tek eksenli sarsma tablas1-deprem simülasyon cihazı yardımıyla yapının dinamik davranışı saptanmaya çalışılmıştır. gerçekleştirilmiştir. Simülasyon cihazı; dinamik veri toplayıcı,sensör ve bilgisayar yazılımından oluşmaktadır. Bilgisayarda bulunana sinyal işleme yazılımı ile deprem ivme kayıtları sarsma tablasına iletilmektedir. 250N servo-elektro motor kapasiteli sarsma tablası, tek eksenli olarak, ölçekli deprem ivme kayıtlarının yanı sıra sinüs, üçgen vb. tanımlı dalgaları, simule edebilme özelliğine sahiptir. Servo motor, kapalı devre PID kontrol sistemi adı verilen; çıkıştan geri besleme yoluyla giriş sinyaline gelen sinyali giriş sinyali ile karşılaştırıp farkını alıp hatayı oluşturup, bu hatayı denetleyicisine gönderen ve denetleyicinin bu sinyali bir katsayı ile çarpıp, türevini ve integralini alarak tekrar çıkışa gönderdiği ve bu şekilde bir döngü içinde hata minimuma inene kadar işlem devam eden bir denetleme sistemi ile otomatik olarak kontrol edilmektedir. Servo motor ile hareketi sağlanan sarsma tablası ile maksimum $\pm 2 \mathrm{~g}$ ivme kapasitesine sahip deprem hareketleri oluşturulabilmektedir (Şekil 4).

Model yapının sarsma etkisi altındaki dinamik davranışının belirlenmesi için ivme ölçerler kullanılmıştır. İvme ölçerlerin hareket doğrultusu, tek eksenli sarsma tablasının hareket doğrultusu paralel olacak şekilde model bina üzerine yerleştirilmiştir. Ayrıca taban yerdeğiştirme ve ivme değerlerinin alınabilmesi için sarsma tablasının üzerine de ivme ölçer yerleştirilmiştir. Tepe noktasında ve tablanın üzerinde bulunan ivme ölçerlerden alınan ivme değerleri, dinamik veri toplama sistemi yardımı ile bilgisayara aktarılmaktadır. Kullanılan ivme ölçerler $\pm 3 \mathrm{~g}$ ölçüm kapasitesinde $0-400 \mathrm{~Hz}$ frekans aralığına sahiptir. İvme ölçerden alınan veriler Sismo signal programı ile işlenmiştir. Sismo signal programında bulunan filitreleme sistemlerinden faydalanılmıştır. 


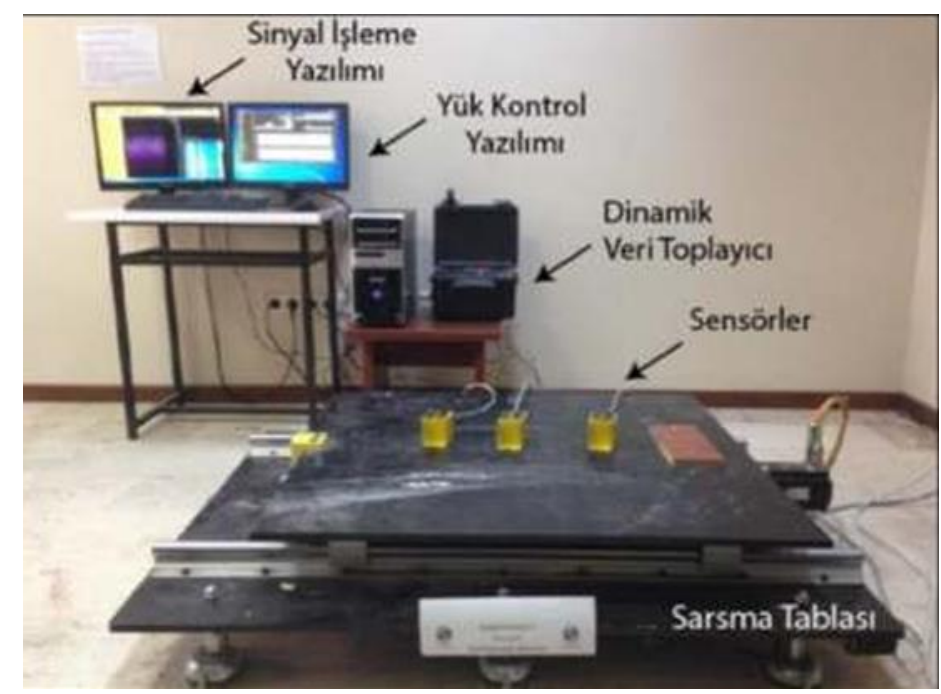

Şekil 4. Deney düzeneği

Model yapı ahşap rijit bir taban plakası üzerine ankastre olacak şekilde montelenmiştir. Taban plakası üzerindeki model yapının sınır şartlarının sağlanmasında ahşap aparat ve bulonlar kullanılmıştır. Yapının taban plakasının etrafi ahşap rijit bloklar ile çevrelenmiş ve ahşap bloklar sarsma tablasına civatalarla ankastre olacak şekilde bağlanarak model yapının hareketi engellenmiştir (Şekil 5).
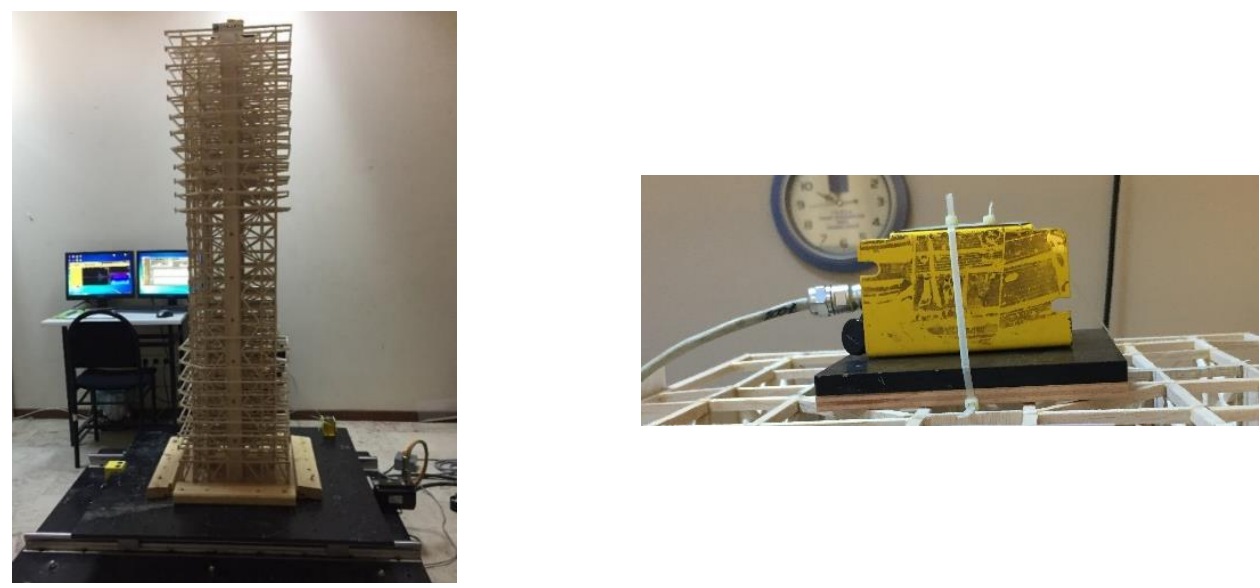

Şekil 5. Model yapının sarsma tablasına yerleştirilmesi ve ivme ölçer

Çalışma kapsamında, model binanın dinamik davranışının belirlenmesi için 3 farklı deprem ivme veri kaydı uygulanmıştır. Tanımlı deprem kayıtları sarsma tablasına iletilmiş ve model bina bu değerler ile sarsılması sağlanmıştır. Uygulanan 3 farklı depremin ivme-zaman kayıtları Şekil 6'da verilmiştir. (Tablo 2)

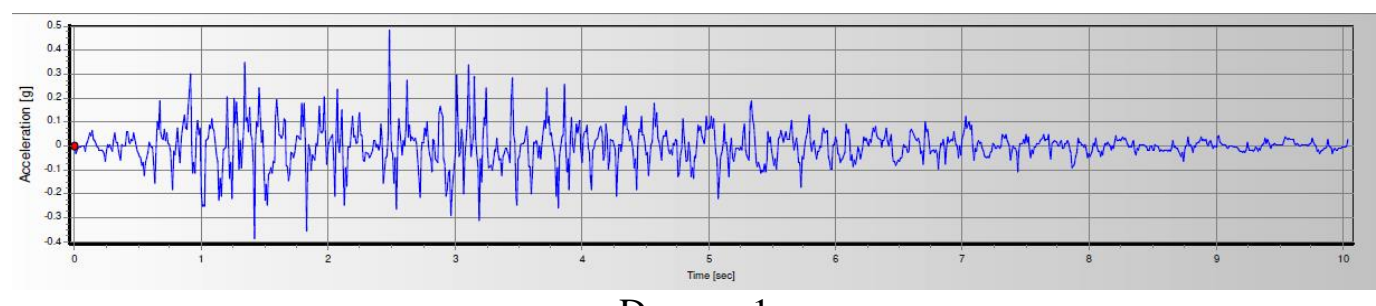

Deprem 1 


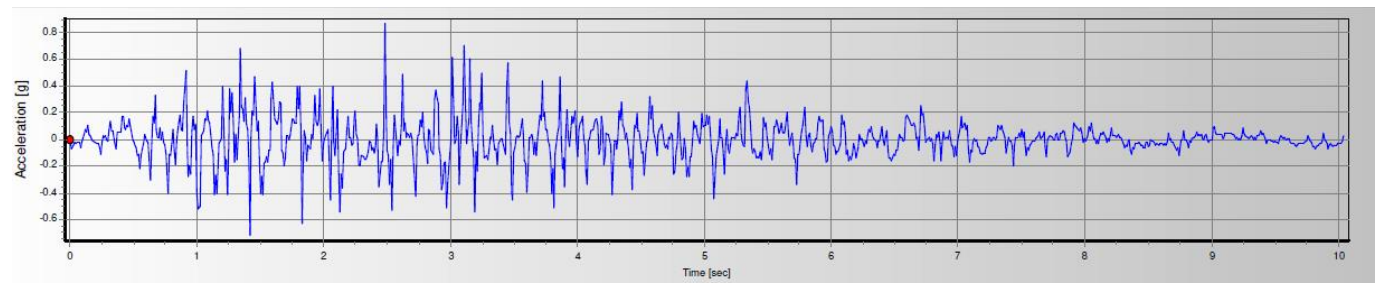

Deprem 2

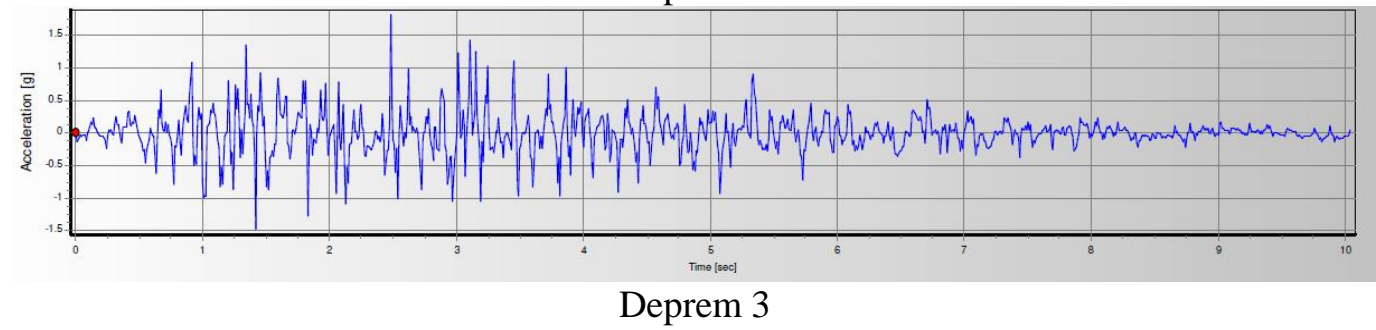

Şekil 6. Model yapıya uygulanan deprem ivme kayıtları

Tablo 2. Deprem1,2,3 ivme-hız-deplasman değerleri

\begin{tabular}{|c|c|c|c|c|c|c|c|}
\hline & \multicolumn{2}{|c|}{$\begin{array}{l}\text { Max İvme } \\
(\mathrm{g})\end{array}$} & \multicolumn{2}{|c|}{$\begin{array}{l}\text { Max. Hiz } \\
\text { (cm/sn) }\end{array}$} & \multicolumn{2}{|c|}{$\begin{array}{l}\text { Max. Yer. Değ. } \\
(\mathrm{mm})\end{array}$} & \multirow{2}{*}{$\begin{array}{l}\mathrm{V}_{\text {max }} / \mathrm{A}_{\text {max }} \\
(\mathrm{sn})\end{array}$} \\
\hline Deprem 1 & 0.482 & $2.48 \mathrm{sn}$ & 9.038 & $2.91 \mathrm{sn}$ & 23.953 & $5.45 \mathrm{sn}$ & \\
\hline Deprem 2 & 0.867 & $2.48 \mathrm{sn}$ & 21.053 & $1.25 \mathrm{sn}$ & 50.659 & $9.8 \mathrm{sn}$ & 0.025 \\
\hline Deprem 3 & 1.812 & $2.48 \mathrm{sn}$ & 38.86 & $3 \mathrm{sn}$ & 92.08 & $9.83 \mathrm{sn}$ & 0.022 \\
\hline
\end{tabular}

\section{SONLU ELEMAN MODELLEMESi}

Model yapı Sap 2000 programı yardımı ile modellenmiştir (Şekil 7). Kolon, kiriş elemanları çubuk eleman (frame eleman) olarak modellenmiş, döşeme ise rijit diyafram kabulü kullanılarak modellenmiştir. Rijit diyafram kabulü, döşeme rijitliğinin düşey taşıyıcı sistem elemanlarının rijitliğine göre büyük olması durumunda kabul edilen bir durumdur. Deneysel çalışma sırasında 3 katta 1 yerleştirilen 1,5 kg ağırlık ile tanımlanan ve rijit diyafram tanımında gerekli olan kütle değeri, sonlu eleman modellemesinde de yapılmıştır. Perdelerin modellenmesinde kabuk (Shell) elemanı kullanıldı ve sonlu eleman genişliği $25 \mathrm{~cm}$ olarak belirlenmiştir. Model binanın sarsma tablası üzerine rijit ahşap bloklar ve bulonlar yardımıyla yapılan montajı, sonlu eleman modelinde ankastre sınır şartı olarak tanımlanmasını sağlamıştır. Sarsma tablası yardımıyla model yapıya etki ettirilmiş olan üç farklı deprem ivme kaydı, SAP 2000 programı ile Zaman Tanım Alanında Hesap Yöntemi (Time History) kullanılarak, yapının sonlu eleman modeli oluşturulmuştur.

Çalışma sonunda, model yapıdan deneysel olarak elde edilen ivme değerleri ve ivme değerlerine bağlı olarak hesaplanan hız ve deplasman değerleri, yapının sonlu eleman modelinin Zaman Tanım Alanında Hesap yöntemi yardımıyla yapılan analiz ile elde edilen ivme-hız-deplasman değerleri ile karşılaştırılmıştır. 


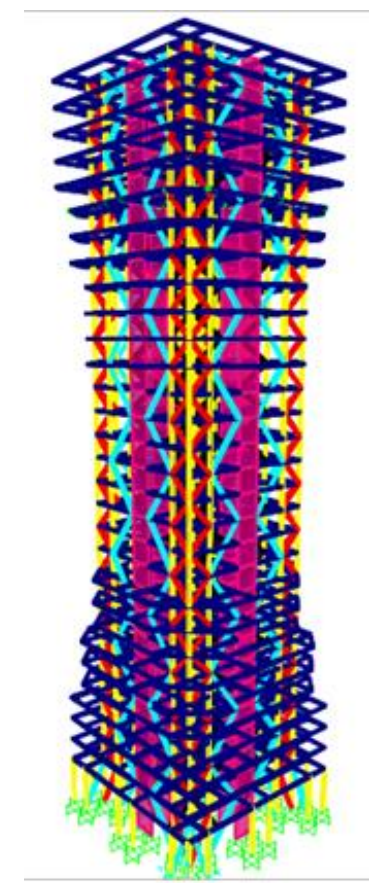

Şekil 7. Model yapı sonlu eleman modeli

\section{ANALIZ SONUÇLARI}

Model yapının doğal frekansını belirlemek için sarsma tablası üzerine ankastre bağlı yapıya serbest titreşim hareketi yaptırılmış, sonrasında yük kontrol yazılımı ile sarsma tablası üzerinde ve sonlu eleman programı yardımı ile üç farklı deprem hareketi uygulanmıştır. Deneysel olarak incelenen model yapıya deney esnasında uygulanan sınır koşulları sonlu eleman modelinde simüle edilmeye çalışılmıştır. Sonuç olarak, model yapının hem deneysel hem sonlu eleman modellemesinden elde edilen sonuçları karşılaştırılmıştır.

Deneysel çalışma ve nümerik çalışma sonucunda model yapı tepe noktası maksimum yer değiştirme ve maksimum ivme değerleri ölçülmüştür. Ölçülen ivme değerleri, ivme kayıtlarının tümü standart olarak sıfır çizgisi düzeltmesi yöntemi ile düzeltilmiş, Sesismosignal programı kullanılarak filtrelenmiştir. Deneysel çalışma ve nümerik çalışma ile ölçülen maksimum ivme değerleri karşılaştırılmıştır (Tablo 3).

Tablo 3. Deneysel çalışma ve Sap2000 modelinden ölçülen tepe noktası ivme değerleri

\begin{tabular}{cccc}
\hline Deprem Kayd 1 & Model yap $1(\mathrm{~g})$ & Sap2000 $(\mathrm{g})$ & Fark \% \\
\hline KYH1 & 0.676 & 0.794 & 17 \\
KYH2 & 1.397 & 1.584 & 13 \\
KYH3 & 2.638 & 3.096 & 17 \\
\hline
\end{tabular}

Deneysel olarak ölçülen tepe noktası ivme-zaman grafiği (Şekil 8) ve sonlu eleman modellemesinden elde edilen tepe noktası ivme-zaman grafikleri (Şekil 9) verilmiştir. 

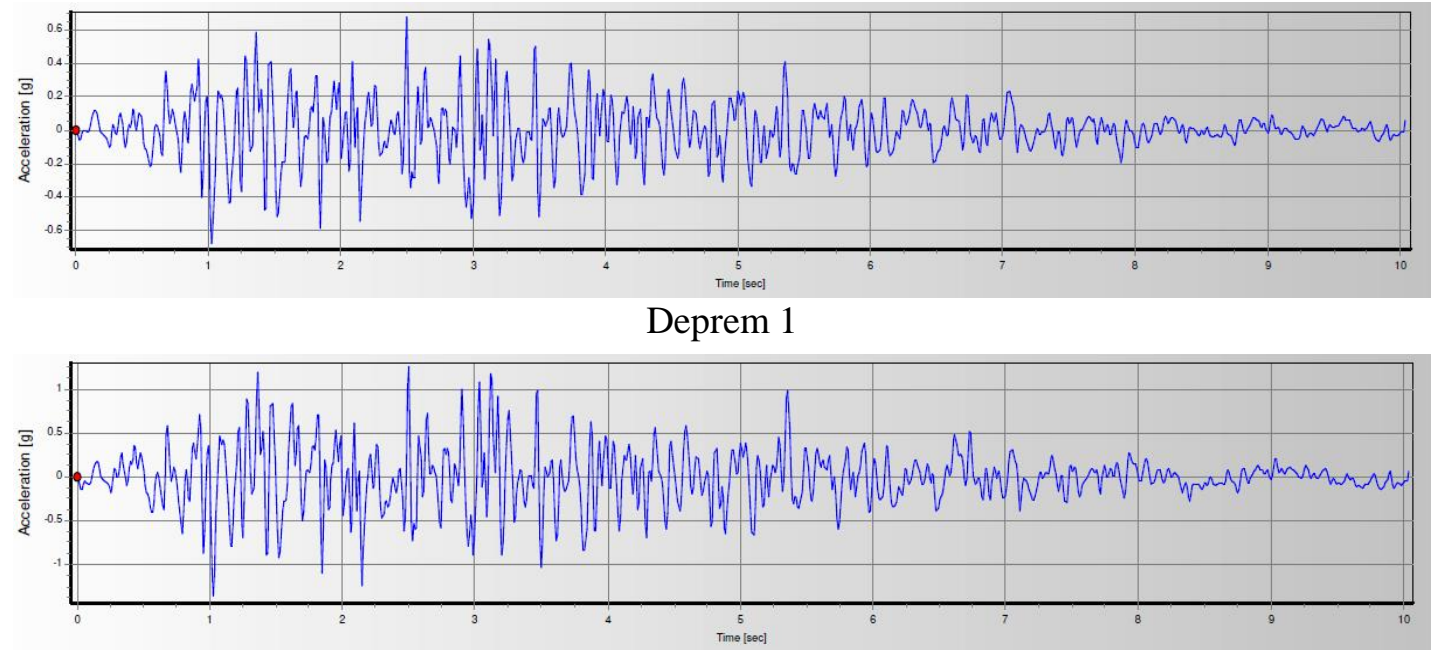

Deprem 2

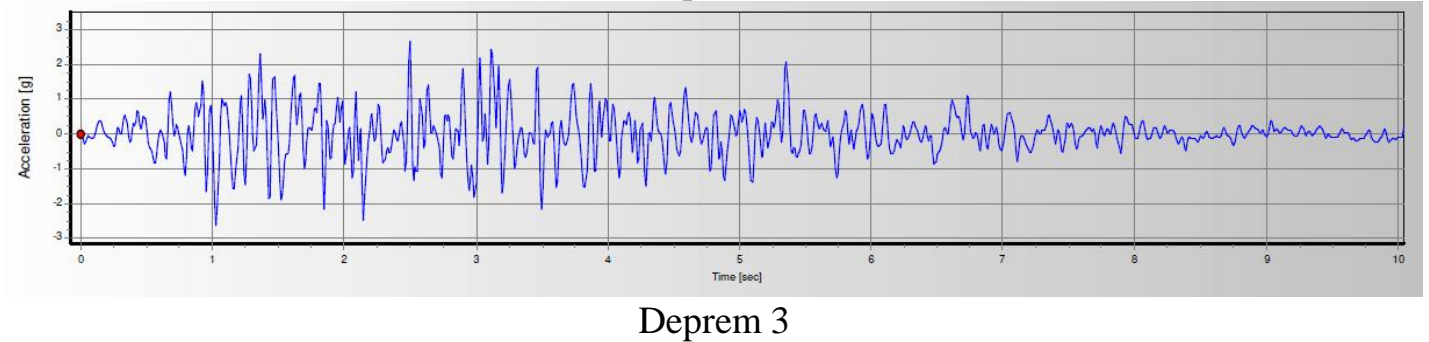

Şekil 8. Model yapı tepe noktası ivme değerleri

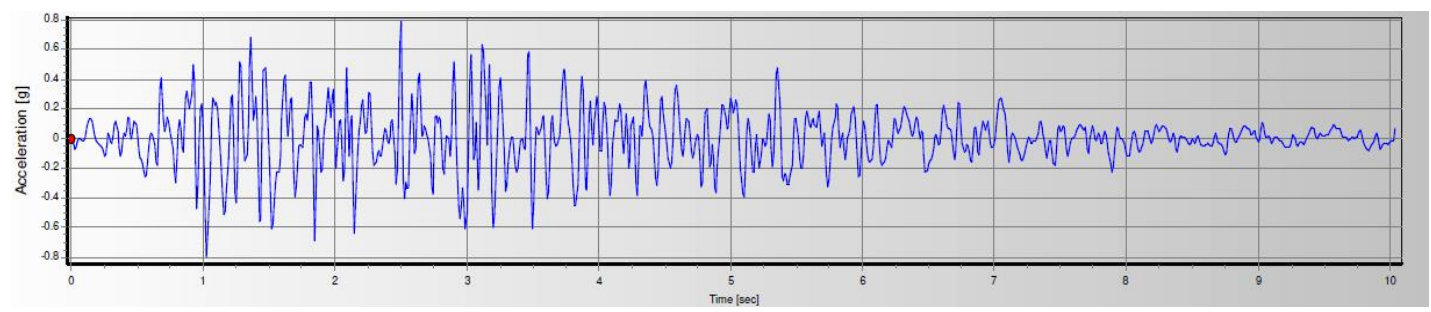

Deprem 1

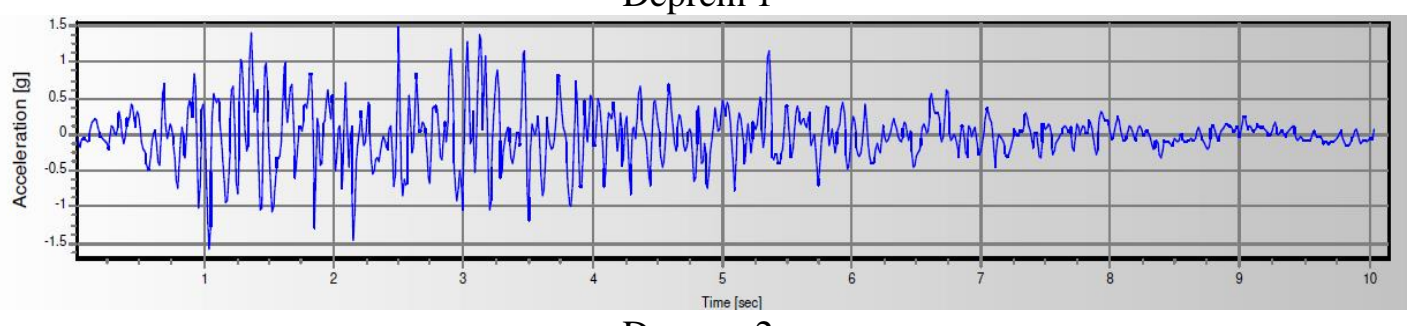

Deprem 2

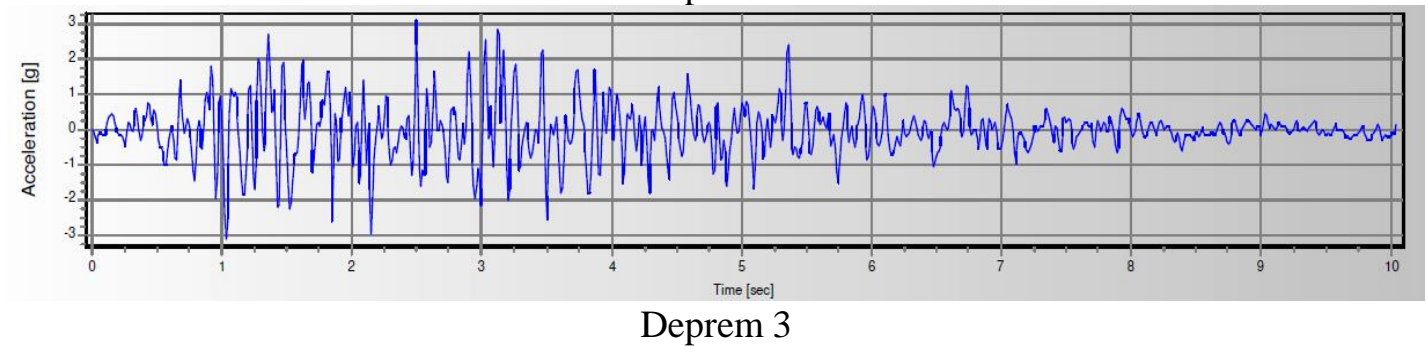

Şekil 9. Yapının sonlu eleman modeli tepe noktası ivme değerleri 


\section{SONUÇ VE TARTIŞMA}

Çalışma kapsamında 30 katlı her iki doğrultuda simetrik perdeli çerçeveli sistemden oluşan bir yapının deneysel ve numerik olarak dinamik karakteristikleri karşılaştırılmıştır. Sarsma tablası ile deprem yüklerine maruz bırakılan model yapıdan ivme ölçerler yardımı ile deneysel veriler alınmış ve sismosignal programı ile işlenmiştir. Tasarlanan yapı modeline kayıtlı deprem ivme değerleri uygulanmış ve maksimum tepe noktası ivme değerleri ölçülmüştür. Nümerik çalışmada Sap 2000 analiz programı kullanılmış, model bina deneysel çalışmadaki sınır koşullarına uygun olarak modellenmiştir. Deneysel çalışmada kullanılan üç farklı deprem yüklemesi, Zaman Tanım Alanında Hesap yöntemi ile nümerik çalışma modeline de uygulanmış ve tepe noktası ivme-zaman, yer değiştirme-zaman değerleri ölçülmüştür. Deneysel çalışma ve nümerik çalışma sonucunda elde edilen değerler incelendiğinde nümerik çalışmanın deneysel çalışmayı destekleyici nitelikte olduğu tespit edilmiştir. Deneysel çalışma ile sonlu eleman modeli arasında \%13-\%17 arasında fark bulunmuştur. Bu farkın en büyük sebebi, deneysel çalışmada kullanılan sınır şartlarının, sonlu eleman modellemesinde tam olarak simule edilememesi ve döşeme kabülünden kaynaklandığ düşünülmektedir. Ancak sonlu eleman modelinden elde edilen ivme değeri ile deneysel çalışmadan elde edilen ivme değeri karşılaştırıldığında, grafiklerin aynı karakteristik davranışa sahip olduğu görülmektedir. Bu durum çalışmada kullanılan kabullerin doğruluğunu göstermektedir.

\section{TEŞEKKÜRLER}

2018 yılında düzenlenen, DASK Depreme Dayanıklı Bina Tasarımı Yarışması maket için gerekli olan malzeme teminini sağlamıştır. Maket model yapımı Hikmet Yılmaz, Emir Tartar, Osman Türk, Osman Azaklı yardımı ile tamamlanmıştır.

\section{REFERANSLAR}

[1] Özmen, G. (2001). Plan Geometrisinin Burulma Düzensizliğine Etkisi. Türkiye Mühendislik Haberleri, 46, 37-41.

[2] Bahçecioğlu, A. Ş. (2015). Planda Düzensiz Yapıların Deprem Etkileri Altındaki Davranışı, Doktora Tezi, Fen Bilimleri Enstitüsü.

[3] Polat, G. (2015). Betonarme Yüksek Yapılarda Kullanılabilecek Taşıyıcı Sistemler Ve Perde-çerçeveli Bir Yapının Statik Ve Dinamik Hesabı Doktora Tezi, İstanbul Teknik Üniversitesi Fen Bilimleri Enstitüsü, İstanbul.

[4] Demir, A. ve Dönmez, D. (2008). Çok Katlı Yapılarda Burulma Düzensizliğine Etki Eden Faktörler. Celal Bayar. Üniversitesi Fen Bilimleri Dergisi, 4(1).

[5] Şahin H, Alyamaç KE, Erdoğan A.S.(2013). Perdeli çerçeveli yapılarda zemin sınıfı ve kat adedi dikkate alınarak gerekli perde oranının tespiti. SDU International Technologic Science. Cilt:5, sayı:1 s:74-86, 2013.

[6] Sayın E, Yön B, Calayır Y.(2010). Perde konumunun ve zemin sınıfının betonarme yapılardaki hasar oranına etkisi. Erciyes Üniversitesi Fen Bilimleri Enstitüsü Dergisi Cilt:26, Sayı:1, s:1-6.

[7] Özsoy AE, Özgen K.(2005). Perdelerdeki boşlukların yatay ötelenmeye etkisi. Deprem Sempozyumu, Kocaeli. 
[8] Işık, M. (2015). Çok Katlı Betonarme Yapılarda Taşıyıcı Sistem Etkisi, Doktora Tezi, Fen Bilimleri Enstitüsü.

[9] Qiu, C., \& Zhu, S. (2017). Shake table test and numerical study of self-centering steel frame with SMA braces. Earthquake Engineering \& Structural Dynamics, 46(1), 117-137.

[10] Goggins, J., Broderick, B. M., Elghazouli, A. Y., Salawdeh, S., Hunt, A., Mongabure, P., \& English, J. (2018). Shake table testing of concentrically braced steel structures with realistic connection details subjected to earthquakes. In Structures (Vol. 13, pp. 102-118). Elsevier.

[11]Fiorino, L., Macillo, V., \& Landolfo, R. (2017). Shake table tests of a full-scale two-story sheathing-braced cold-formed steel building. Engineering Structures, 151, 633-647.

[12] Fiorino, L., Bucciero, B., \& Landolfo, R. (2019). Shake table tests of three storey cold-formed steel structures with strap-braced walls. Bulletin of Earthquake Engineering, 17(7), 4217-4245.

[13] Nasery, M. M., Hüsem, M., Okur, F. Y., \& Altunişik, A. C. (2019). Damage effect on experimental modal parameters of haunch strengthened concrete-encased composite column-beam connections. International Journal of Damage Mechanics, 1056789519843330.

[14] http://www.hazarahsap.com.tr/Balsa

[15] Chopra AK.(2015). Yapı Dinamiği teori ve deprem mühendisliği uygulamaları. 4. Baskıdan çeviri, Ankara: Palme Yayınc1lik.

[16] S. Karaahmetli, C. Dündar(2017). Yapı Sönüm Oranının Belirlenmesinde Kullanılan Yöntemlerin Sayısal ve Deneysel Olarak İncelenmesi, 4. Uluslararası Deprem Mühendisliği ve Sismoloji Konferansı, Eskişehir.

[17] Hüsem, M., Nasery, M. M., Okur, F. Y., \& Altunişik, A. C. (2018). Experimental evaluation of damage effect on dynamic characteristics of concrete encased composite column-beam connections. Engineering Failure Analysis, 91, 129-150.

[18] Hüsem, M., Nasery, M. M., Okur, F. Y., \& Altunişik, A. C. (2018). Experimental evaluation of damage effect on dynamic characteristics of concrete encased composite column-beam connections. Engineering Failure Analysis, 91, 129-150.

Geliş/Received: 30 Haz 2019/30 Jun 2019

Kabul Ediliş/Accepted: 13 Eki 2019/13 Oct 2019 